\title{
Cationic Micellar Precipitation for Simultaneous Preconcentration of Benzimidazole Anthelmintics in Milk Samples by High-Performance Liquid Chromatography
}

\author{
Jitlada Vichapong, ${ }^{* a}$ Yanawath Santaladchaiyakit, ${ }^{b}$ Supalax Srijaranaic ${ }^{c}$ and \\ Rodjana Burakham ${ }^{c}$
}

${ }^{a}$ Creative Chemistry and Innovation Research Unit, Department of Chemistry and Center of Excellence for Innovation in Chemistry, Faculty of Science, Mahasarakham University, 44150 Mahasarakham, Thailand

${ }^{b}$ Department of Chemistry, Faculty of Engineering, Rajamangala University of Technology Isan, Khon Kaen Campus, 40000 Khon Kaen, Thailand

${ }^{c}$ Materials Chemistry Research Center, Department of Chemistry and Center of Excellence for Innovation in Chemistry, Faculty of Science, Khon Kaen University, 40002 Khon Kaen, Thailand

\begin{abstract}
A method using micellar precipitation process using cationic surfactant cetyltrimethyl ammonium bromide at ambient temperature was investigated for simultaneous determination of benzimidazoles coupled with high-performance liquid chromatography (HPLC) analysis. The studied benzimidazoles was selected as model compounds including thiabendazole, albendazole, mebendazole, and fenbendazole. The experimental parameters affected the extraction efficiency, including the kind and concentration of salt, $\mathrm{pH}$, concentration of CTAB, volume of 1-octanol, and the centrifugation extraction time, was optimized. The optimum extraction condition: $0.030 \mathrm{~mol} \mathrm{~L}^{-1}$ $\mathrm{CTAB}, 10 \%(\mathrm{~m} / \mathrm{v}) \mathrm{NaCl}, \mathrm{pH} 4.0,300 \mu \mathrm{L}$ 1-octanol and centrifugation time $10 \mathrm{~min}$. Under optimum conditions, enrichment factors of between 60 and 90 fold were obtained, leading to lower limit of detection in the range of $0.5-0.7 \mu \mathrm{g} \mathrm{L}^{-1}$, depending on the analytes. The calibration range of the method was linear over the wide range of $0.5-1000 \mu \mathrm{g} \mathrm{L}^{-1}$, with correlation coefficients more than 0.999. Finally, the proposed method was successfully applied in the analysis of benzimidazoles in milk samples.
\end{abstract}

Keywords: cationic micellar precipitation, HPLC, benzimidazoles, extraction

\section{Introduction}

Sample preparation is one of the most important and necessary step before instrumental analysis. Good sample preparation allows not only the analyte to be preconcentrated but also remove the other compounds present in the sample matrix. Conventional sample preparation methods have been used including liquid-liquid extraction (LLE) ${ }^{1}$ and solid-phase extraction (SPE). ${ }^{2,3}$ However, big disadvantages are the large quantities of solvent utilized and the multiple operation steps needed. ${ }^{4}$ Recently, attention is being paid to the development of miniaturized, more efficient and environmentally friendly extraction techniques that could greatly reduce the toxic organic solvent consumption. ${ }^{5}$ Alternative extraction approaches based on surfactant (e.g., non-ionic, anionic, and cationic), namely cloud-point extraction or micelle-mediated

*e-mail: jitlada.v@msu.ac.th extraction have also been generally approved as a powerful method for sample preparation. Its major advantages are low cost, simple experimental procedures, high preconcentration factors, personal and environmental safety. ${ }^{6-9}$ During the past years, cloud point extraction has become one of the most preferred preconcentration methodologies as "green technology" owing to its following unique characteristics: (i) it uses an inexpensive surfactant extractant; (ii) it generates less laboratory waste; and (iii) its surfactants are less toxic, not volatile and not inflammable, unlike organic solvents used in LLE. ${ }^{7}$ It was used as a preconcentration method in simultaneous determination of various compounds (e.g., pesticides, antibiotics, pollutants, etc.) in different sample matrices. ${ }^{10-14}$ This method has some disadvantages such as time-consuming, and requires a temperature control and centrifugation for phase separation.

Cationic micellar precipitation (CMP) has been introduced as a new extraction and pre-concentration method 
for the analysis of cadmium, cobalt and nickel in water samples. ${ }^{6}$ In this method, the extractant is dispersed into the aqueous solution with precipitation solvent as dispersant. The use of precipitation solvent as an emulsifier solvent in CMP can accelerate the formation of the fine droplets of the extraction solvent in an aqueous sample solution, which increase the dispersion of the water immiscible phase into the aqueous phase, and enhance the mass transfer of the analytes from the aqueous phase to the organic phase.

Benzimidazole anthelmintic drugs are commonly used for prevention and treatment of parasitic infections in agriculture, aquaculture and veterinary practices..$^{15-17}$ However, there may be a concern that if withdrawal periods are not adhered to, or if products are administered to animals in unapproved applications, the levels may exceed maximum residue limits (MRLs) in foods. ${ }^{15}$ The MRL values range from 10 to $5000 \mu \mathrm{g} \mathrm{kg}^{-1}$ depending on the compound and biological matrix. ${ }^{18}$ Therefore, the development of sensitive, effective, and reliable analytical methods is still required to monitor these residues in food samples.

Because of wide spread use and possible health effects, it is desirable to monitor benzimidazoles in the food samples. Gas chromatography (GC) was also applied while extra derivatization step of residues to sufficiently volatilize was required. ${ }^{19}$ Capillary electrophoresis $(\mathrm{CE})^{20}$ has also been applied in the separation of benzimidazole anthelmintic drugs, but suffers from low sensitivity because of small sample volumes injected and less sensitive detection systems that are employed. High performance liquid chromatography (HPLC) coupled with various detection systems, i.e., ultraviolet (UV), ${ }^{3,21,22}$ fluorescence (FL), ${ }^{23}$ mass spectrometry (MS) $)^{24,25}$ and both UV and $\mathrm{MS}^{26}$ have been accepted as popular and powerful tools for the analysis of benzimidazoles.

This work focuses on the development of the method for the extraction using cationic micellar precipitation (CMP) for benzimidazoles coupled with HPLC analysis. Four benzimidazoles (i.e., thiabendazole, albendazole, mebendazole, and fenbendazole) were selected as model compounds. CTAB were used as precipitating agents in extraction method. This is the first time for hyphenation of a simple CMP system with HPLC for benzimidazole applications.

\section{Experimental}

\section{Chemicals and reagents}

The standards of benzimidazoles of highest purity were purchased from Sigma-Aldrich including thiabendazole (Italy), mebendazole (USA), albendazole and fenbendazole (China). The chemical structures of the studied benzimidazoles evaluated here are shown in Table 1. The stock standard solutions of each benzimidazole (1000 $\left.\mathrm{mg} \mathrm{L}^{-1}\right)$ were prepared by dissolving each benzimidazole standard in $5 \%(\mathrm{v} / \mathrm{v})$ formic $\mathrm{acid} / \mathrm{methanol}$. Methanol and acetonitrile (ACN) of HPLC grade were obtained from Merck (Germany). $\mathrm{NaCl}$ and anhydrous $\mathrm{Na}_{2} \mathrm{SO}_{4}$ were obtained from Ajax Finechem (New Zealand) and $\mathrm{CH}_{3} \mathrm{COONa}$ was purchased from Carlo Erba (France). Cetyltrimethyl ammonium bromide (CTAB) was purchased from Calbiochem (Germany). CTAB was prepared in water before use. Acetic acid (glacial), formic acid and 1-octanol were obtained from Merck (Germany). Deionized water was obtained from $\mathrm{RiOs}^{\mathrm{TM}}$ Type I Simplicity 185 (Millipore Waters, USA) with the resistivity of $18.2 \mathrm{M} \Omega \mathrm{cm}$ and was used throughout the experiments.

\section{Chromatographic conditions}

The HPLC system comprised a Waters 600 multisolvent delivery system, a Rheodyne injector with a sample loop of $20 \mu \mathrm{L}$, a Waters 996 photodiode array detector and were recorded at $296 \mathrm{~nm}$. The Millennium software was used for data acquisition. The separation of benzimidazoles was carried out on an Atlantis dC18 column $(4.6 \times 150 \mathrm{~mm}$, $5.0 \mu \mathrm{m}$ ) from Water (Ireland) with gradient elution using $\mathrm{MeOH}$ and $0.1 \%$ (v/v) acetic acid, a flow rate of $1.0 \mathrm{~mL} \mathrm{~min}^{-1}$ and detection at $296 \mathrm{~nm}$. The gradient elution was performed as follows: $60 \%$ (v/v) $\mathrm{MeOH}(0-3 \mathrm{~min})$, ramped to $95 \%(\mathrm{v} / \mathrm{v}) \mathrm{MeOH}$ (3-10 min). After that, $100 \%$ (v/v) MeOH was held for 5 min to wash the excess surfactant from the system. Finally, $60 \%$ (v/v) MeOH was held ( $5 \mathrm{~min}$ ) to equilibrate the column before the next run.

\section{Cationic micellar precipitation (CMP) procedure}

An aliquot of a standard (or sample solution) was mixed with $\mathrm{NaCl}(10 \%, \mathrm{~m} / \mathrm{v})$. After that, $1.0 \mathrm{~mL}$ of conc. $\mathrm{HCl}$ was added and shaken by hand for a minute. The sample solution was rapidly injected with $300 \mu \mathrm{L}$ precipitation solvent $\left(0.30 \mathrm{~mol} \mathrm{~L}^{-1} \mathrm{CTAB}\right)$ and $300 \mu \mathrm{L}$ extraction solvent (1-octanol) using 1-mL syringe. After that, the solution was centrifuged at 3,500 rpm for $10 \mathrm{~min}$ to complete the phase separation. The sediment phase floated on the top of the solution due to its density that is lower than that of water. The upper phase was collected and then directly injected into HPLC for analysis.

Milk sample analysis

The studied cow milk samples were commercial 
Table 1. The chemical structures of the studied benzimidazoles

\begin{tabular}{|c|c|c|c|c|c|}
\hline Analyte & Structure & $\begin{array}{l}\text { Molar mass / } \\
\quad\left(\mathrm{g} \mathrm{mol}^{-1}\right)\end{array}$ & $\begin{array}{c}\text { Octanol/ } \\
\text { water partition } \\
\text { coefficient }\end{array}$ & $\mathrm{pKa}$ & $\begin{array}{c}\text { Melting } \\
\text { point } /{ }^{\circ} \mathrm{C}\end{array}$ \\
\hline Thiabendazole (TBZ) & & 201.2 & $\begin{array}{c}2.2(\mathrm{pH} 5) \\
2.4(\mathrm{pH} 9)\end{array}$ & 4.64 at $25^{\circ} \mathrm{C}$ & 293 to 305 \\
\hline Mebendazole (MBZ) & & 295.2 & 2.8 & 8.44 & 288.5 \\
\hline Albendazole (ABZ) & & 265.3 & 1.57 & 6.90 & 208 to 210 \\
\hline Fenbendazole (FBZ) & & 299.3 & 3.85 & - & 233 \\
\hline
\end{tabular}

UHT and pasteurized milk. The commercial milks were purchased from a supermarket in Mahasarakham province (Thailand). Milk samples were pretreated using the slightly modified procedure from our previous work. ${ }^{16}$ Before analysis, a $5.00 \mathrm{~mL}$ of milk samples were mixed well with $0.2 \mathrm{~g}$ of anhydrous $\mathrm{Na}_{2} \mathrm{SO}_{4}$. After that, $1 \%$ (v/v) acetic acid in ACN $(5.00 \mathrm{~mL})$ was added and shaken vigorously by vortex agitation. Then, the homogenized milk samples were centrifuged at 3,500 rpm for $5 \mathrm{~min}$ for complete fat and protein precipitation. The supernatants were filtered through Whatman filter paper No. 1. The solutions were diluted with water to $10.00 \mathrm{~mL}$ in volumetric flasks. The $100 \mu \mathrm{L}$ of acetic acid were added and centrifuged again to ensure complete fat and protein precipitation. Then, the clear solutions were subjected to cationic micellar precipitation procedure, and the extract phase was then analyzed by HPLC. For spiked samples, the samples were fortified with the target analytes at different concentrations $\left(0.05,0.10\right.$, and $\left.0.50 \mathrm{mg} \mathrm{L}^{-1}\right)$ before fat and protein precipitation. All experiments were performed in triplicate.

\section{Results and Discussion}

\section{Optimization of the cationic micellar precipitation procedure}

To obtain the most favorable conditions of cationic micellar precipitation procedure, various parameters were studied including the kind and concentration of salt, $\mathrm{pH}$, concentration of CTAB, volume of 1-octanol, and centrifugation time. The optimization was carried out on the aqueous solution containing $0.10 \mathrm{mg} \mathrm{L}^{-1}$ of each analytes. The extraction efficiency was evaluated in term of enrichment factor (EF), which was defined as the ratio between the analyte concentration in extraction solvent after and before the extraction process. ${ }^{27}$ All experiments were operated at least in triplicate.

Generally, the addition of salt decreases the solubility of the analytes in aqueous samples and enhances their distribution into the organic phase. ${ }^{28}$ Thus, addition of different electrolyte salts $\left(\mathrm{NaCl}, \mathrm{Na}_{2} \mathrm{SO}_{4}\right.$ and $\mathrm{CH}_{3} \mathrm{COONa}$ ) at $10 \%(\mathrm{~m} / \mathrm{v})$ was investigated to study the influence of ionic strength and the results were compared with that obtained from the process without salt addition. From the results (Figure 1), it is clearly seen that the addition of $\mathrm{NaCl}$ provided higher extraction efficiency in term of peak area of neonicotinoids. Consequently, the concentration of $\mathrm{NaCl}$ on the extraction efficiency of the target analyte were also studied within the range of $0-40 \%(\mathrm{~m} / \mathrm{v})$. The results in Figure 2 demonstrated an improvement of extraction efficiency for all analytes when $10 \%(\mathrm{~m} / \mathrm{v})$ $\mathrm{NaCl}$ was added, and the extraction efficiency decreased because sediment phase increased. Therefore, $10 \%(\mathrm{~m} / \mathrm{v})$ $\mathrm{NaCl}$ was selected.

Sample pH plays an important role in the extraction procedure because $\mathrm{pH}$ value determines the existing form of the analytes, and then the $\mathrm{pH}$ of the sample solution affects the extraction efficiency. ${ }^{29}$ The effects of $\mathrm{pH}$ were studied in the range of 3-9 (data not shown). The conditions of all the other variables were kept constant: sample solution $(10.00 \mathrm{~mL}), \mathrm{NaCl} 10 \%(\mathrm{~m} / \mathrm{v}), 300 \mu \mathrm{L}$ of 


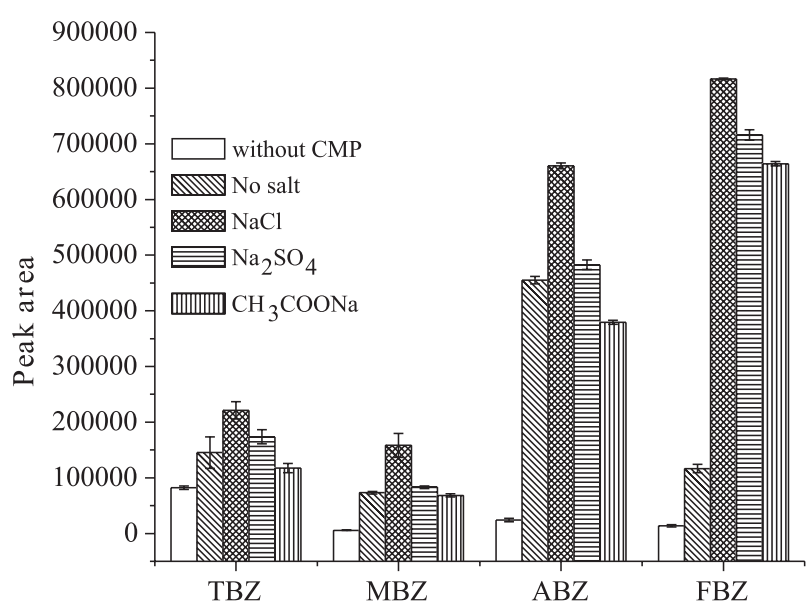

Figure 1. Effect of kind of salt on the CMP of benzimidazoles. The conditions of all the other variables kept constant: sample solution $(10.00 \mathrm{~mL})$, sample $\mathrm{pH} 4,300 \mu \mathrm{L}$ of extraction solvent, $0.30 \mathrm{~mol} \mathrm{~L}^{-1}$ CTAB surfactant, and 3,500 rpm for $10 \mathrm{~min}$.

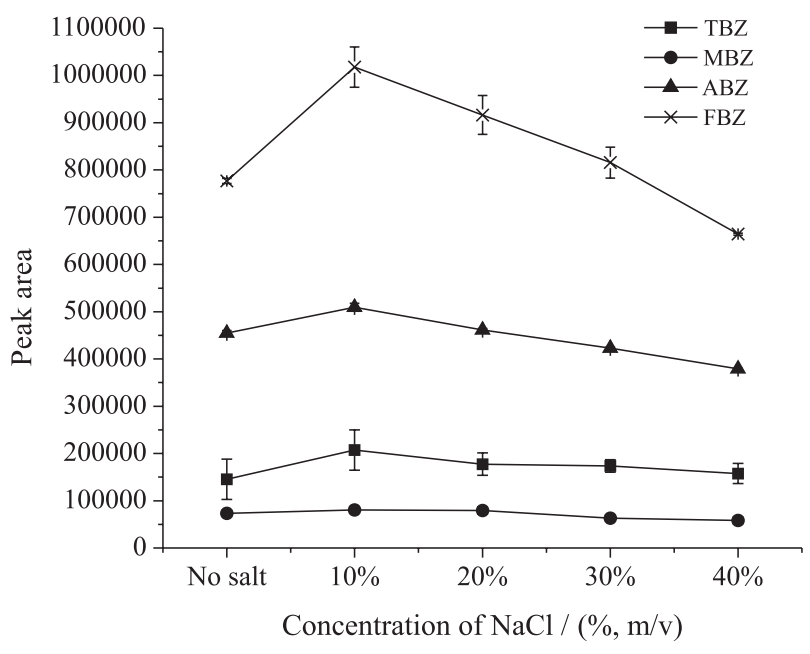

Figure 2. Effect of concentration of salt on the CMP of benzimidazoles. The conditions of all the other variables kept constant: sample solution (10.00 mL), sample $\mathrm{pH} 4,300 \mu \mathrm{L}$ of extraction solvent, $0.30 \mathrm{~mol} \mathrm{~L}^{-1}$ CTAB surfactant, and 3,500 rpm for $10 \mathrm{~min}$.

extraction solvent, $0.030 \mathrm{~mol} \mathrm{~L}^{-1}$ CTAB surfactant, and $3,500 \mathrm{rpm}$ for $10 \mathrm{~min}$. It was found that the $\mathrm{pH} 4$ provided high extraction efficiency in term of peak area. Therefore, $\mathrm{pH} 4$ was selected in this study.

Surfactant could increase the dispersion of extraction solvent into the aqueous solution, thus improving the extraction efficiency. Different concentrations of CTAB were investigated in the range of $0.13-1.00 \mathrm{~mol} \mathrm{~L}^{-1}$. The results are shown in Figure 3. It can be seen that, the peak area increased by increasing CTAB concentration up to $0.30 \mathrm{~mol} \mathrm{~L}^{-1}$. Beyond this point, the peak areas of all benzimidazoles kept constant. It is noticed that the optimum CTAB concentration $\left(0.30 \mathrm{mmol} \mathrm{L}^{-1}\right)$ is higher than its micellar concentration of CTAB $\left(0.92 \mathrm{mmol} \mathrm{L}^{-1}\right)$. Therefore, $0.030 \mathrm{~mol} \mathrm{~L}^{-1} \mathrm{CTAB}$ concentration was chosen as an optimum value.

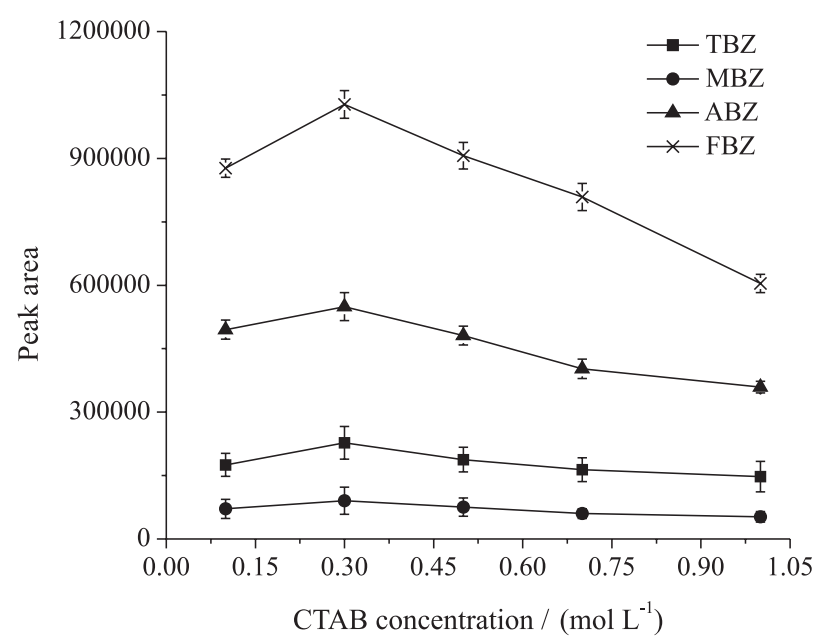

Figure 3. Effect of concentration of $\mathrm{CTAB}$ on the $\mathrm{CMP}$ of benzimidazoles. The conditions of all the other variables kept constant: sample solution

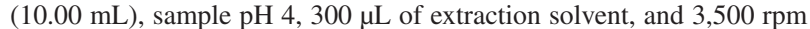
for $10 \mathrm{~min}$.

The effect of extraction solvent volume (1-octanol) were studied between 50 and $1000 \mu \mathrm{L}$ (data not shown). It was found that, the extraction solvent volume of $50 \mu \mathrm{L}$ was too low to provide three replicate measurements. Moreover, the 1-octanol more than $300 \mu \mathrm{L}$ decreased the peak area of benzimidazoles. Therefore, $300 \mu \mathrm{L}$ of 1-octanol was selected.

In general, centrifugation time is required to accelerate phase separation between two phases in extraction procedure; so the influence of centrifugation time on the peak area was examined. A series of centrifugation extraction times was studied in the range of 5-30 min at $3,500 \mathrm{rpm}$. The conditions of all the other variables were kept constant: sample solution $(10.00 \mathrm{~mL})$, sample $\mathrm{pH} 4$, $300 \mu \mathrm{L}$ of extraction solvent, and $0.30 \mathrm{~mol} \mathrm{~L}^{-1} \mathrm{CTAB}$ surfactant. The extraction performance of benzimidazoles slightly increased with increasing the time up to $10 \mathrm{~min}$ and then kept constant, therefore $10 \mathrm{~min}$ was chosen to ensure the extraction performance of the proposed method.

\section{Analytical performance of the method}

Table 2 summarizes the analytical characteristics of the optimized method, including regression equation, linear range, limit of detection, limit of quantification and repeatability of the analytes determined after CMP-HPLC analysis. Linear equations in the range of $0.005-1 \mathrm{mg} \mathrm{L}^{-1}$ with high correlation coefficients $\left(\mathrm{r}^{2}>0.999\right)$ were obtained. The relative standard deviation (RSD) was determined using five solutions of the $0.002 \mathrm{mg} \mathrm{L}^{-1}$ of each benzimidazoles. The RSD values of the retention times and peak areas ranged $0.18-0.37 \%$ and $1.43-2.54 \%$, respectively. The sensitivity was evaluated in term of LOD as concentration 
Table 2. Analytical performance of the method

\begin{tabular}{|c|c|c|c|c|c|c|c|c|c|c|c|}
\hline \multirow{3}{*}{ Benzimidazole } & \multicolumn{5}{|c|}{ HPLC } & \multicolumn{6}{|c|}{ CMP-HPLC } \\
\hline & \multirow{2}{*}{$\begin{array}{l}\text { Linear } \\
\text { range / } \\
\left(\mathrm{mg} \mathrm{L}^{-1}\right)\end{array}$} & \multirow{2}{*}{$\begin{array}{l}\mathrm{LOD}^{\mathrm{a}} / \\
\left(\mathrm{mg} \mathrm{L}^{-1}\right)\end{array}$} & \multirow{2}{*}{$\begin{array}{c}\mathrm{LOQ}^{\mathrm{b}} / \\
\left(\mathrm{mg} \mathrm{L}^{-1}\right)\end{array}$} & \multicolumn{2}{|c|}{$\operatorname{RSD}^{\mathrm{c}}(\mathrm{n}=6) / \%$} & \multirow{2}{*}{$\begin{array}{l}\text { Linear } \\
\text { range / } \\
\left(\mathrm{mg} \mathrm{L}^{-1}\right)\end{array}$} & \multirow{2}{*}{$\begin{array}{c}\text { LOD / } \\
\left(\mathrm{mg} \mathrm{L}^{-1}\right)\end{array}$} & \multirow{2}{*}{$\begin{array}{c}\mathrm{LOQ} / \\
\left(\mathrm{mg} \mathrm{L}^{-1}\right)\end{array}$} & \multicolumn{2}{|c|}{$\operatorname{RSD}(\mathrm{n}=6) / \%$} & \multirow{2}{*}{$\mathrm{EF}^{\mathrm{d}}$} \\
\hline & & & & $t_{R}$ & Peak area & & & & $t_{R}$ & Peak area & \\
\hline TBZ & $0.03-5$ & 0.01 & 0.03 & 0.32 & 1.76 & $0.005-1$ & 0.0005 & 0.001 & 0.25 & 1.77 & 60 \\
\hline MBZ & $0.03-5$ & 0.01 & 0.03 & 0.15 & 2.84 & $0.005-1$ & 0.0005 & 0.001 & 0.37 & 1.65 & 60 \\
\hline $\mathrm{ABZ}$ & $0.10-5$ & 0.03 & 0.10 & 0.28 & 2.63 & $0.007-1$ & 0.0007 & 0.002 & 0.28 & 2.54 & 90 \\
\hline FBZ & $0.03-5$ & 0.01 & 0.03 & 0.14 & 3.45 & $0.005-1$ & 0.0005 & 0.001 & 0.18 & 1.43 & 60 \\
\hline
\end{tabular}

HPLC: high-performance liquid chromatography; CMP-HPLC: cationic micellar precipitation-HPLC; LOD: limit of detection; LOQ: limit of quantification; RSD: relative standard deviation; EF: enrichment factor.

giving the signal-to-noise ratio of $3(\mathrm{~S} / \mathrm{N}=3)$ and ranged between $0.0005-0.0007 \mathrm{mg} \mathrm{L}^{-1}$. The LOQ $(\mathrm{S} / \mathrm{N}=10)$ ranged between 0.001 and $0.002 \mathrm{mg} \mathrm{L}^{-1}$. The enhancement factors, calculated by comparing the slopes of the calibration graphs with and without preconcentration, were in the range of 60-90. The chromatograms obtained for the separation of benzimidazoles by direct HPLC injection (Figure 4) and CMP combined with HPLC (Figure 5) were compared.

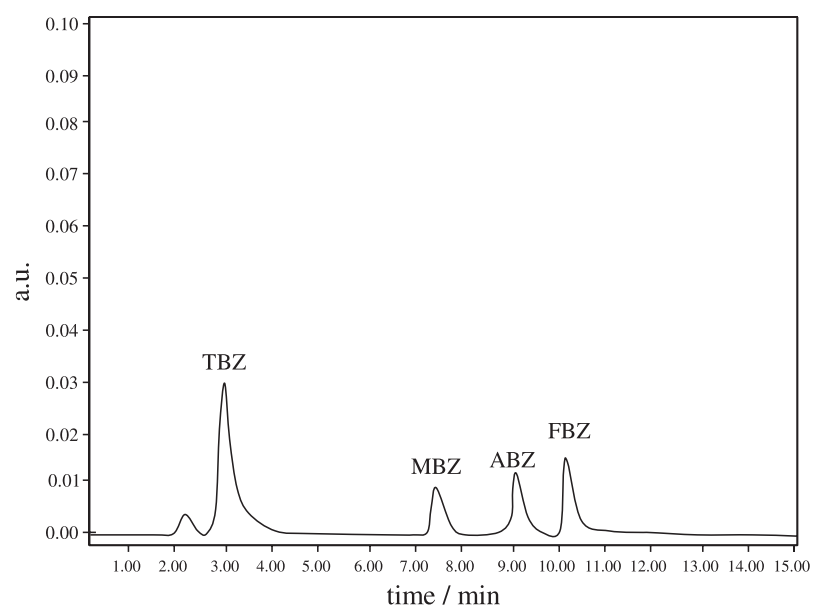

Figure 4. Chromatogram of the studied benzimidazoles obtained from benzimidazoles $\left(2.00 \mathrm{mg} \mathrm{L}^{-1}\right)$ without pre-concentration (direct analysis).

\section{Application to real samples}

To evaluate the applicability and accuracy of the developed CMP method in real milk sample determination, each sample was pre-treated as described in Milk sample analysis section, and then extracted using the CMP procedure (see Cationic micellar precipitation (CMP) procedure section) before analysis by HPLC. The results are summarized in Table 3. It was observed that some benzimidazoles was found in the studied pasteurized milk samples. However, the amounts of benzimidazoles found in the pasteurized milk samples were lower than the maximum residue limits (MRLs) established by EU (liver tissue,

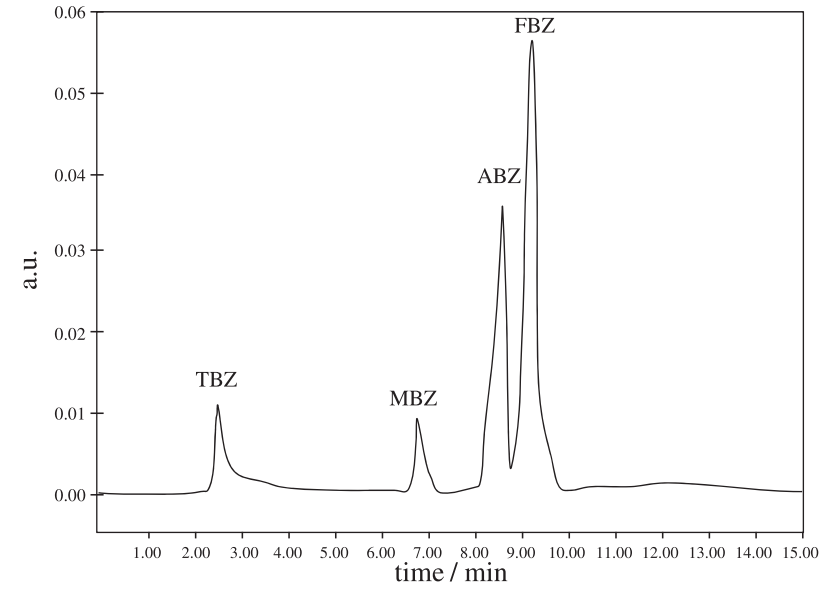

Figure 5. Chromatogram of the studied benzimidazoles $\left(0.10 \mathrm{mg} \mathrm{L}^{-1}\right)$ with preconcentration using CMP condition: $0.30 \mathrm{~mol} \mathrm{~L}^{-1} \mathrm{CTAB}, 10 \%$ $(\mathrm{m} / \mathrm{v}) \mathrm{NaCl}, \mathrm{pH} 4.0,300 \mu \mathrm{L}$ 1-octanol and centrifugation time $10 \mathrm{~min}$.

$100-1000 \mu \mathrm{g} \mathrm{kg}^{-1}$; kidney and muscle, $50-500 \mu \mathrm{g} \mathrm{kg}^{-1}$; fat 50-200 $\mu \mathrm{g} \mathrm{kg}^{-1}$, milk 10-100 $\mu \mathrm{g} \mathrm{kg}^{-1}$ ).

The recovery experiments were carried out to investigate the method accuracy and precision. The samples were spiked with standard benzimidazoles at three concentration levels of $0.05,0.10$ and $0.50 \mathrm{mg} \mathrm{L}^{-1}$ before analysis by the whole analytical processes proposed. As listed in Table 4, the recoveries were observed in the range of $87-106 \%$ for pasteurized milk samples. Figures 6 and 7 show the typical chromatograms of the studied samples.

\section{Conclusions}

The proposed method gives a precise, sensitive and selective cationic micellar precipitation (CMP) procedure for the simultaneous preconcentration and determination of benzimidazoles coupled with HPLC system. The extraction was performed at ambient temperature in the absence of any organic dispersive solvent and showed reliability with well suited analytical detection range for application in milk samples. CMP for benzimidazoles provides high 
Table 3. Analysis of benzimidazole anthelmintics in real samples

\begin{tabular}{lcccc}
\hline \multirow{2}{*}{ Sample } & \multicolumn{3}{c}{ Amount found $\pm \mathrm{SD}(\mathrm{n}=3) /\left(\mathrm{mg} \mathrm{L}^{-1}\right)$} \\
\cline { 2 - 5 } & Thiabendazole & Mebendazole & Albendazole & Fenbendazole \\
\hline Pasteurized milk 01 & $0.04 \pm 0.01$ & - & $1.72 \pm 0.13$ & - \\
Pasteurized milk 02 & $0.05 \pm 0.02$ & $0.03 \pm 0.01$ & - & $1.45 \pm 0.35$ \\
Pasteurized milk 03 & $0.08 \pm 0.02$ & - & - & - \\
Pasteurized milk 04 & $0.04 \pm 0.01$ & - & - & $0.88 \pm 0.05$ \\
UHT milk 01 & - & - & - \\
\hline
\end{tabular}

SD: standard deviation; -: not detected.

Table 4. Recoveries of the studied benzimidazoles in spiked samples

\begin{tabular}{|c|c|c|c|c|c|c|c|c|c|}
\hline \multirow{2}{*}{ Sample } & \multirow{2}{*}{$\begin{array}{l}\text { Spiked / } \\
\left(\mathrm{mg} \mathrm{L}^{-1}\right)\end{array}$} & \multicolumn{2}{|c|}{ Thiabendazole } & \multicolumn{2}{|c|}{ Mebendazole } & \multicolumn{2}{|c|}{ Albendazole } & \multicolumn{2}{|c|}{ Fenbendazole } \\
\hline & & $\mathrm{RR} / \%$ & RSD / \% & $\mathrm{RR} / \%$ & RSD / \% & $\mathrm{RR} / \%$ & RSD / \% & $\mathrm{RR} / \%$ & $\mathrm{RSD} / \%$ \\
\hline & 0.05 & 90 & 1.2 & 93 & 1.7 & 97 & 2.4 & 95 & 1.3 \\
\hline \multirow[t]{3}{*}{ Pasteurized milk 01} & 0.10 & 98 & 2.7 & 106 & 2.2 & 99 & 1.7 & 95 & 1.8 \\
\hline & 0.50 & 95 & 2.4 & 101 & 2.4 & 88 & 1.5 & 97 & 2.1 \\
\hline & 0.05 & 105 & 1.2 & 94 & 2.5 & 93 & 1.7 & 89 & 2.2 \\
\hline \multirow[t]{3}{*}{ Pasteurized milk 02} & 0.10 & 99 & 1.6 & 107 & 1.8 & 95 & 1.8 & 102 & 2.5 \\
\hline & 0.50 & 97 & 2.3 & 98 & 1.9 & 92 & 1.8 & 96 & 2.4 \\
\hline & 0.05 & 93 & 2.8 & 88 & 2.6 & 94 & 2.5 & 97 & 2.7 \\
\hline \multirow[t]{3}{*}{ Pasteurized milk 03} & 0.10 & 89 & 2.8 & 93 & 2.2 & 102 & 2.6 & 99 & 1.6 \\
\hline & 0.50 & 98 & 2.5 & 105 & 2.5 & 108 & 1.9 & 93 & 3.1 \\
\hline & 0.05 & 90 & 2.7 & 100 & 1.9 & 105 & 1.9 & 98 & 1.8 \\
\hline \multirow[t]{3}{*}{ Pasteurized milk 04} & 0.10 & 92 & 1.6 & 98 & 1.8 & 106 & 1.6 & 98 & 2.5 \\
\hline & 0.50 & 93 & 1.9 & 99 & 1.9 & 98 & 1.8 & 87 & 2.7 \\
\hline & 0.05 & 91 & 1.7 & 105 & 1.7 & 98 & 2.1 & 95 & 2.3 \\
\hline \multirow[t]{2}{*}{ UHT milk 01} & 0.10 & 95 & 2.1 & 101 & 2.2 & 94 & 2.5 & 98 & 1.9 \\
\hline & 0.50 & 93 & 2.4 & 102 & 2.1 & 97 & 2.7 & 96 & 1.6 \\
\hline
\end{tabular}

RR: relative recovery (on average, $n=3$ ); RSD: relative standard deviation.

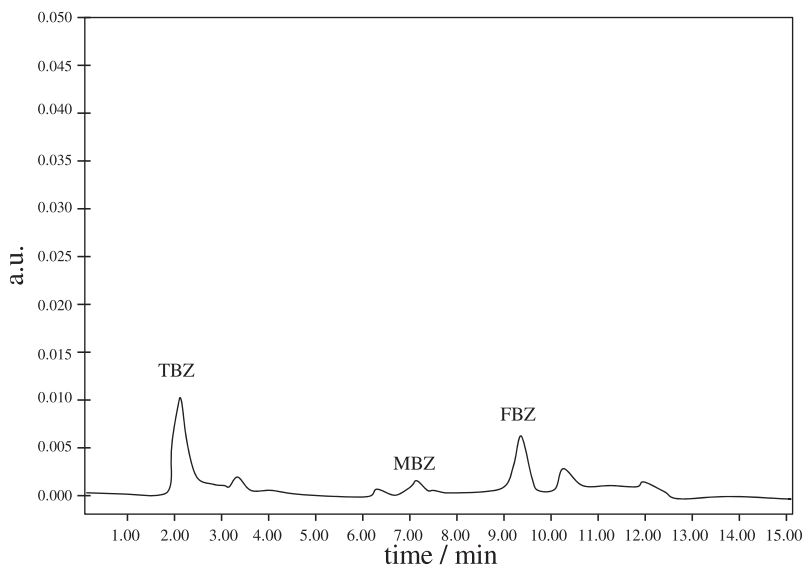

Figure 6. Chromatogram of pasteurized milk 02 by CMP method. The extraction conditions: sample solution $(10.00 \mathrm{~mL})$, sample $\mathrm{pH} 4,300 \mu \mathrm{L}$ of extraction solvent, $0.30 \mathrm{~mol} \mathrm{~L}^{-1} \mathrm{CTAB}$ surfactant, and 3,500 rpm for $10 \mathrm{~min}$.

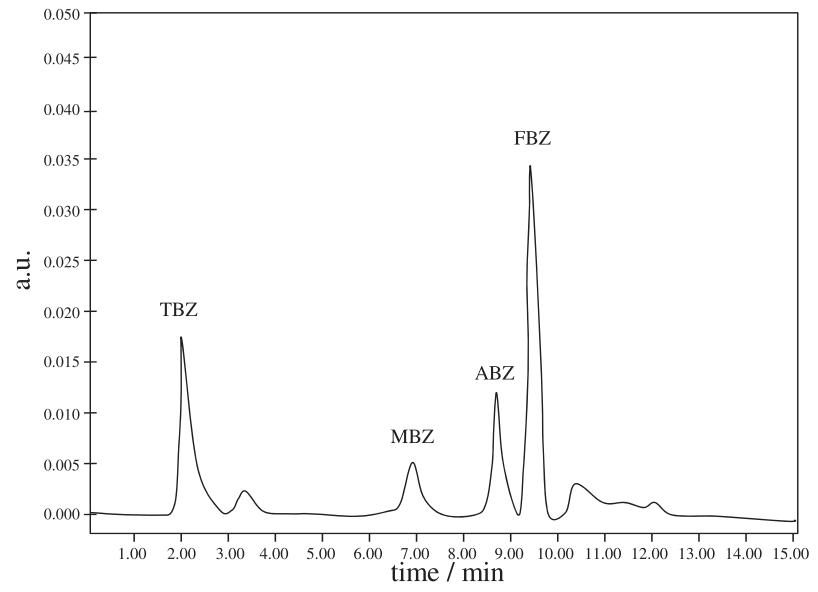

Figure 7. Chromatogram of pasteurized milk 02 with spiked benzimidazole standard ( $0.05 \mathrm{mg} \mathrm{L}^{-1}$ each) by CMP method. The extraction conditions: sample solution $(10.00 \mathrm{~mL})$, sample $\mathrm{pH} 4,300 \mu \mathrm{L}$ of extraction solvent, $0.30 \mathrm{~mol} \mathrm{~L}^{-1} \mathrm{CTAB}$ surfactant, and 3,500 rpm for $10 \mathrm{~min}$. 
efficacy for extraction with the obtained enrichment factor ranging from 60 to 90 . To the best of our knowledge this extraction technique has not been reported in the literature and it is being used for the first time for the analysis of benzimidazoles coupled with HPLC.

\section{Acknowledgments}

This article is dedicated to Professor Dr. Kate Grudpan (Chiang Mai University, Thailand) in celebration of his $60^{\text {th }}$ birthday. J. Vichapong gratefully acknowledges financial supports for this research from Center of Excellence for Innovation in Chemistry (PERCH-CIC), National Research Council of Thailand (NRCT), the Commission on Higher Education (CHE), The Thailand Research Fund (TRF) and Mahasarakham University, for the research scholar (Grant No. TRG5780060).

\section{References}

1. Jedziniak, P.; Szprengier-Juszkiewicz, T.; Olejnik, M.; J. Chromatogr. A 2009, 1216, 8165.

2. Caprioli, G.; Cristalli, G.; Galarini, R.; Giacobbe, D.; Ricciutelli, M.; Vittori, S.; Zuo,Y.; Sagratini, G.; J. Chromatogr. A 2010, 1217, 1779.

3. Chen, D.; Tao, Y.; Liu, Z.; Liu, Z.; Lingli, H.; Wang, Y.; Pan, Y.; Peng, D.; Dai, M.; Yuan, Z.; J. Chromatogr. A 2010, 878, 2928.

4. Santaladchaiyakit, Y.; Srijaranai, S.; Anal. Methods 2012, 4, 3864.

5. Vichapong, J.; Burakham, R.; Srijaranai, S.; Grudpan, K.; Talanta 2011, 84, 1253.

6. Beiraghi, A.; Babaee, S.; Roshdi, M.; Microchem. J. 2012, 100, 66.

7. Bezerra, M. A.; Arruda, M. A. Z.; Ferreira, S. L. C.; Appl. Spectrosc. Rev. 2005, 40, 269.

8. Lemos, V. A.; David, G. T.; Microchem. J. 2010, 94, 42.

9. Matos, G. D.; Reis, E. B.; Costa, A. C. S.; Ferreira, S. L. C.; Microchem. J. 2009, 92, 135.

10. Liu, X.; Chen, X.-H.; Zhang, Y.-Y.; Liu, W.-T.; Bi, K.-S.; J. Chromatogr. B 2007, 856, 273.

11. Wang, L.; Cai, Y.-Q.; He, B.; Yuan, C.-G.; Shen, D.-Z.; Shao, J.; Jiang, G.-B.; Talanta 2006, 70, 47.
12. Santalad, A.; Srijaranai, S.; Burakham, R.; Sakai, T.; Deming, R. L.; Microchem. J. 2008, 90, 50.

13. Goryacheva, I. Y.; Loginov, A. S.; Lavrova, T. N.; Popov, M. A.; J. Anal. Chem. 2007, 62, 411.

14. Goryacheva, I. Y.; Shtykov, S. N.; Loginov, A. S.; Panteleeva, I. V.; Anal. Bioanal. Chem. 2005, 382, 1413.

15. Danaher, M.; Ruyck, H. D.; Crooks, S. R. H.; Dowling, G.; O'Keeffe, M.; J. Chromatogr. B 2007, 845, 1.

16. Santaladchaiyakit, Y.; Srijaranai, S.; Food Anal. Methods 2013, $6,1551$.

17. Vichapong, J.; Santaladchaiyakit, Y.; Burakham, R.; Kanchanamayoon, W.; Srijaranai, S.; J. Food Comp. Anal. 2015, 37, 30 .

18. European Commission; Commission Regulation (EU) No. 37/2010 of 22 December 2009 on Pharmacologically Active Substances and Their Classification Regarding Maximum Residue Limits in Foodstuffs of Animal Origin; Official Journal of the European Union, 2010, L15, p. 1.

19. Hu, X.-Z.; Chen, M.-L.; Gao, Q.; Yu, Q.-W.; Feng, Y.-Q.; Talanta 2012, 89, 335.

20. Domínguez-Álvarez, J.; Mateos-Vivas, M.; García-Gómez, D.; Rodríguez-Gonzalo, E.; Carabias-Martínez, R.; J. Chromatogr. A 2013, 1278, 166.

21. Mottier, L.; Alvarez, L.; Lanusse, C.; J. Chromatogr. B 2003, 798, 117.

22. Danaher, M.; O'Keeffe, M.; Glennon, J. D.; Anal. Chim. Acta 2003, $483,313$.

23. Wu, Q.; Li, Y.; Wang, C.; Liu, Z.; Zang, X.; Zhou, X.; Wang, Z.; Anal. Chim. Acta 2009, 638, 139.

24. Hu, X.-Z.; Wang, J.-X.; Feng, Y.-Q.; J. Agric. Food Chem. 2010, $58,112$.

25. Msagati, T. A. M.; Nindi, M. M.; Talanta 2006, 69, 243.

26. Msagati, T. A. M.; Nindi, M. M.; J. Sep. Sci. 2001, 24, 606.

27. Vichapong, J.; Burakham, R.; Srijaranai, S.; Talanta 2013, 117, 221.

28. Seebunrueng, K.; Santaladchaiyakit, Y.; Srijaranai, S.; Anal. Bioanal. Chem. 2012, 404, 1539.

29. Huang, Y.; Zhou, Q.; Xie, G.; Chemosphere 2013, 90, 338.

Submitted: June 22, 2016

Published online: July 29, 2016 